Note

\title{
The Morphological and Biochemical Changes in Skeletal Muscle Fibers by Dietary Protein Restriction
}

\author{
Noriko TANAKA, ${ }^{1}$ Tetsu HAYAKAwA, ${ }^{2}$ Katsuya Zyo, ${ }^{2}$ \\ and Seiki HoRI ${ }^{3}$ \\ ${ }^{1}$ Laboratory of Food Hygiene, Faculty of Home Economics, Kobe Women's University, \\ 2-1 Aoyama Higashisuma, Suma, Kobe 654, Japan \\ ${ }^{2}$ Department of Anatomy, and ${ }^{3}$ Department of Physiology, \\ Hyogo College of Medicine, 1-1 Mukogawacho, \\ Nishinomiya 663, Japan \\ (Received May 19, 1992)
}

\begin{abstract}
Summary The effects of dietary protein restriction on skeletal muscle fibers were studied according to morphological and biochemical approaches. Protein and DNA content of quadriceps muscles from young adult rats were decreased by the low protein and protein-free diet. Morphological examination demonstrated that there was a significant decrease in the size of muscle fibers without change in their numbers due to protein restriction. The protein/DNA ratio, accepted as an index of cell size in biochemical approaches, was compared with cell size on photomicrographs. Actual fiber size appeared much smaller than that indicated by the protein/DNA ratio.

Key Words dietary protein restriction, low protein diet, protein-free diet, morphological change, number of muscle fiber, muscle fiber size, skeletal muscle, quadriceps muscle, protein content, DNA content
\end{abstract}

Before weaning, undernourished animals fed approximately half the ad libitum fed diet of the control had significant deficit in body weight, muscle weight, and total number of muscle fibers (1). Nutritional rehabilitation did not restore such deficits to normal levels in rats undernourished early in life (2), while rehabilitation did so in rats undernourished later in life. The effects of early undernutrition on muscle development may be permanent, probably because a persisting deficit in the number of muscle fibers makes recovery impossible. Later undernutrition may not cause such permanent deficit, since the number of muscle fibers is already fixed early in life $(3,4)$ and is not changed thereafter. However, a decrease in the number of muscle fibers was observed during starvation which caused a $35-45 \%$ loss of body weight in postweaning and young rats (5). Exercise induced increases in muscle fiber number in cat (6). The number of muscle fibers would thus not appear to remain constant throughout life. 
Muscle protein content reflects the amount of the cytoplasmic mass under normal condition of constant relationship between the cell water and protein. DNA content is constant within a single diploid nucleus; therefore, protein/DNA ratio can give an index of average cell volume or size (7-10). Although the protein/DNA ratio is generally accepted by researchers using biochemical approaches, biochemical parameters have never been compared with morphological parameters for the same muscle. We therefore attempted to study the effects of protein deficiency in diet on skeletal muscle growth by both morphological and biochemical approaches.

\section{MATERIALS AND METHODS}

Male 7 -week-old Sprague-Dawley rats were housed individually in wirebottom cages. They were allotted at random into three experimental groups so that all groups were of similar body weight. The three groups of five rats each were fed a diet containing 20,5 , or $0 \%$ casein, respectively. The $20 \%$ casein diet served as the normal growth control. All animals were given food and water ad libitum. The composition (\%) of the $20 \%$ casein diet was: milk casein, 20; cornstarch, 53; sugar 5; cellulose, 8; safflower oil, 6; mineral mixture, 6; vitamin mixture, 2. The mineral and vitamin mixtures were purchased from Oriental Yeast (Tokyo, Japan). The 5, and $0 \%$ casein diets were similar to the control diet except that casein was replaced with cornstarch.

After three weeks of feeding the experimental diets, the animals were weighed and sacrificed. The quadriceps muscles from the right hindlimb were dissected, quickly frozen in liquid nitrogen, and stored at $-80^{\circ} \mathrm{C}$ until chemical analysis. The right muscles were weighed and homogenized with perchloric acid for DNA extraction. DNA was measured by the method of Burton (11) and protein was determined by the method of Lowry.

The quadriceps muscles from the left hindlimb were used for morphological examination. The whole quadriceps muscle was removed and fixed by $10 \%$ formalin. Transverse block of muscle was taken from mid-point and embedded in paraffin. Transverse sections were made at a thickness of $10 \mu \mathrm{m}$ and stained with hematoxylin and eosin. The total number of muscle fibers from M. rectus femoris was counted on photomicrographs of the sections. The area of muscle fibers was determined by an IBAS image processing system (Kontron, Munich, Germany) from the photomicrograph of the sections used to count muscle fibers.

\section{RESULTS AND DISCUSSION}

At 3 weeks of feeding, the respective weights of quadriceps muscle in the LPD (rats fed low protein diet) and PFD (rats fed protein-free diet) groups were 70\% and $50 \%$ of control value. The reduced ratios in the weight were very similar to the parameters in the protein content. Muscle protein content was reduced as dietary 
protein level was decreased. Muscle growth was interrupted in the PFD more severely than in the LPD group as a matter of course.

DNA content was relatively stable and was affected less than protein content. In both the LPD and PFD groups, muscle DNA content was decreased to the same extent, being $70 \%$ of the control value. Gordon et al. (12) found that total DNA content of quadriceps muscle was increased during a growth period and reached to a fixed level in 90 days. The present results, using 7-week-old rats during a period of increasing DNA, indicate that dietary protein restriction reduces DNA content probably due to inhibition of DNA increment during the experimental period. The effects of inhibition of DNA increment in PFD and LPD groups were very similar. Even severe protein restriction such as by a protein-free diet did not reduce muscle DNA content less than $70 \%$ of control value. Muscle protein and DNA thus appear to change differently.

As skeletal muscle has a multinucleated nature, it is impossible to calculate fiber number from a measure of total DNA within the muscle. The total number of muscle fibers from the rectus femoris was thus counted on photomicrographs. The total numbers of the muscle fibers in LPD and PFD groups were increased by 4-8\% as compared with control value, although there was no significant difference between them. The slight increase of muscle fibers is not due to an error in counting fiber number. As the boundaries of the muscle fibers were clearly visible in all three groups (Fig. 1), reliable estimates of total fiber number were always made. Possible explanation would be that dietary protein restriction prevented a loss of fibers which could occur during growth in normal animals (13). Fusion of immature fiber may possibly occur during normal growth (14), leading to a loss of fibers. Thus, the slight increase of fiber number in LPD and PFD groups may occur as a result of lack of fiber fusion. At any rate the number of muscle fibers would not likely be much affected by severe protein restriction (Table 1). Bedi et al. (1) observed that muscles from rats undernourished after weaning and given half the ad libitum fed diet of the control showed no significant deficit in total fiber number. This is consistent with the present observations. They also found that undernutrition before weaning caused significant and permanent deficit in total fiber number. Even after weaning, starvation could cause a decrease in muscle fibers $(5,15)$. Thus, dietary protein or energy restriction alone would not affect muscle fiber number. A constant number of muscle fiber and decreased DNA content should then lead to a decrease of DNA content for each fiber due to protein restriction.

Researchers using biochemical approaches believe that protein/DNA ratio gives a good index for muscle cell volume or size. Protein/DNA ratios for the LPD and PFD groups were $90 \%$ and $70 \%$ of control value, respectively. Both the biochemical and morphological approaches provided another good index of cell size such as protein content per fiber. Protein content per fiber, as determined by dividing mean absolute protein content of muscle fibers by the number of muscle fibers, was $70 \%$ and $48 \%$ of control value for the LPD and PFD groups, respectively. The changes in the protein/fiber were greater than those in pro- 


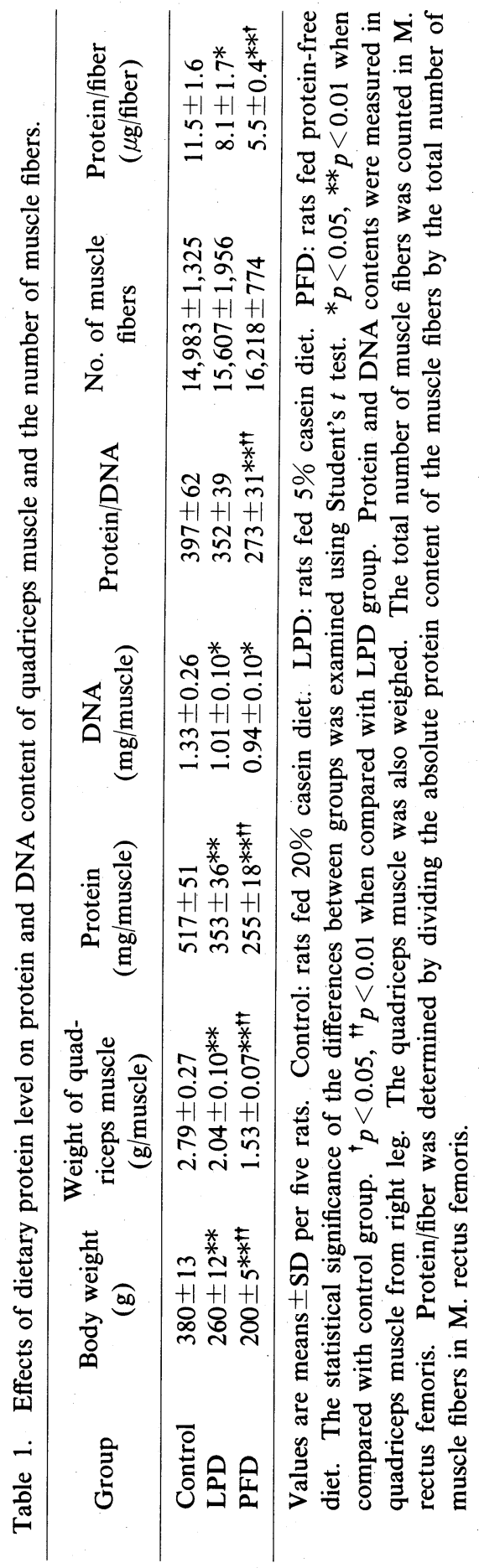




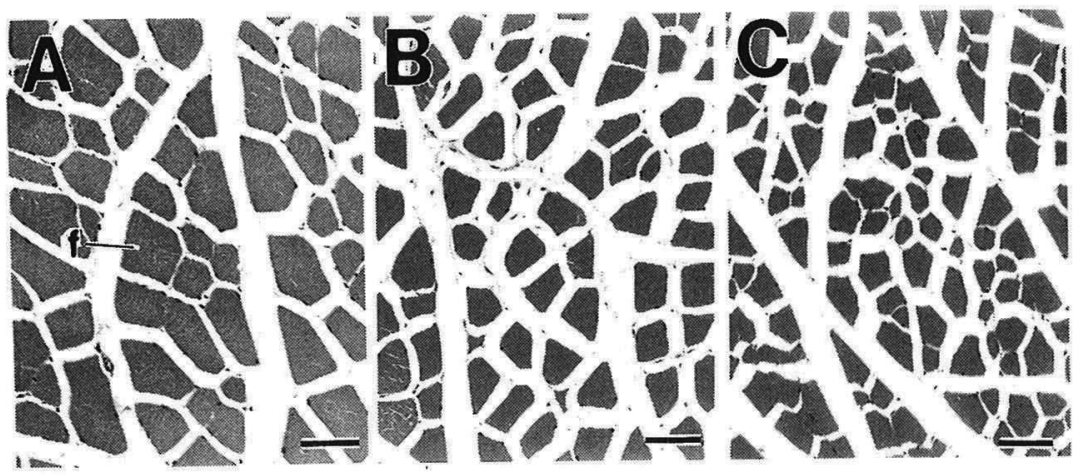

Fig. 1. Photomicrographs of three cases of the rectus femoris muscle. A, normal protein diet. B, low protein diet. c, protein-free diet. f, muscle fiber. Hematoxylineosin stain. $(\times 120)$ (scale, $50 \mu \mathrm{m})$.

tein/DNA.

Actual cell size was measured on photomicrographs and expressed as the cross-sectional area. The mean area of one hundred fibers was 1,551 \pm 787 (SD) $\mu \mathrm{m}^{2}$ for the control group, $1,028 \pm 342$ (SD) $\mu \mathrm{m}^{2}$ for the LPD group and $554 \pm 283$ (SD) $\mu \mathrm{m}^{2}$ for the PFD group (Fig. 1). The mean cross-sectional area of fibers was decreased to about $66 \%$ of control value for LPD and about $36 \%$ for PFD group. The decreased ratios were considerably less than those of protein/DNA ratio, although very similar to those of protein/fiber. Protein/fiber rather than protein/DNA ratio would thus appear to catch changes of the actual size of muscle fiber. It follows then that actual cell size may be much less than the biochemical index. Hansen-Smith et al. (16) found that mean diameters of muscle fibers were 60 $\mu \mathrm{m}$ for the control and 33-43 $\mu \mathrm{m}$ for the protein-restricted group ( $8 \%$ casein). This supports the possibility of a smaller actual fiber size.

In conclusion, the low protein and protein-free diets decreased muscle protein and DNA contents, leading to significant morphological changes. Morphological examination demonstrated that there is a great decrease in the size of muscle fibers without a significant change in the number of muscle fibers. In the quadriceps muscle from protein-restricted rats, actual fiber size appeared much smaller than that expressed in protein/DNA ratio.

\section{REFERENCES}

1) Bedi, K. S., Birzgalis, A. R., Mahon, M., Smart, J. L., and Wareham, A. C. (1982): Early life undernutrition in rats. 1. Quantitative histology of skeletal muscles from underfed young and refed adult animals. Br. J. Nutr., 47, 417-431.

2) Winick, M., and Noble, A. (1966): Cellular response in rats during malnutrition at various ages. J. Nutr., 89, 300-306. 
3) Montgomery, R. D. (1962): Growth of human striated muscle. Nature, 195, 194-195.

4) Enesco, M., and Puddy, D. (1964): Increase in the number of nuclei and weight in skeletal muscle of rats of various ages. Am. J. Anat., 114, 235-244.

5) Hegarty, P. V. J., and Kim, K. O. (1980): Changes in skeletal muscle cellularity in starved and refed yound rats. Br. J. Nutr., 55, 123-127.

6) Gonyea, W. J., Sale, D. G., Gonyea, F. B., and Mikesky, A. (1986): Exercise induced increases in muscle fiber number. Eur. J. Appl. Physiol., 44, 137-141.

7) Cheek, D. B., and Hill, D. E. (1970): Muscle and liver cell growth: Role of hormones and nutritional factors. Fed. Proc., 29, 1503-1509.

8) El Haj, A. J., Lewis, S. E. M., Goldspink, D. F., Merry, B. J., and Holehan, A. M. (1986): The effect of chronic and acute dietary restriction on the growth and protein turnover of fast and slow types of rat skeletal muscle. Comp. Biochem. Physiol., 85A, 281-287.

9) Hill, D. E., Holt, A. B., Parra, A., and Cheek, D. B. (1970): The influence of protein-calorie versus calorie restriction on the body composition and cellular growth of muscle and liver in weanling rats. Johns Hopkins Med. J., 127, 146-163.

10) Hansen-Smith, F. M., Picou, D., and Golden, M. H. (1979): Growth of muscle fibres during recovery from severe malnutrition in Jamaican infants. Br. J. Nutr., 41, 275282.

11) Burton, K. (1956): A study of the conditions and mechanism of the diphenylamine reaction of the colorimetric estimation of deoxyribonucleic acid. Biochem. J., 62, 315323.

12) Gordon, E. E., Kowalski, K., and Fritts, M. (1966): Muscle proteins and DNA in rat quadriceps during growth. Am. J. Physiol., 210, 1033-1040.

13) Bendall, J. R., and Voyle, C. A. (1967): A study of the histological changes in the growing muscles of beef animals. J. Food Technol., 2, 259-283.

14) Layman, D. K., Hegarty, P. V. J., and Swan, P. B. (1980): Comparison of morphological and biochemical parameters of growth in rat skeletal muscles. J. Anat., 130, 159-171.

15) Kim, K. O., and Hegarty, P. V. J. (1978): Effect of total starvation on the number and size of fibres in different skeletal muscles from the young of four species. Proc. Nutr. Soc., 37, 114A.

16) Hansen-Smith, F. M., Van Horn, D. L., and Maksud, M. G.(1978): Cellular response of rat quadriceps muscle to chronic dietary restrictions. J. Nutr., 108, 248-255. 